\title{
Caliper simulation using computer for vocational and technical education
}

\author{
Garip Genc ${ }^{1 \mathrm{a}}$, Sakir Sezen ${ }^{1}$, Nihat Akkus ${ }^{2}$, Ersin Toptas ${ }^{2}$ \\ ${ }^{1}$ Marmara University, Vocational School of Technical Sciences, Istanbul, 34722, Turkey \\ ${ }^{2}$ Marmara University, Faculty of Technology, Istanbul, 34722, Turkey
}

\begin{abstract}
In this study a caliper simulation was developed as computer application for using in the Vocational Education and Training (VET) and Distance-based training. This simulation was developed for teaching the caliper as measurement tool based Metric and Whitworth measurement systems. The developed caliper simulation introduced in detail step by step as user guide. The vernier scales are simulated as $1 / 10,1 / 20$ and $1 / 50$ for metric measurement system and 1/64, 1/128 and 1/1000 for Whitworth measurement system. This simulation can easily be download and setup as computer software. To the best of the authors' knowledge, this is the most important application for students to study everywhere they would like.
\end{abstract}

Keywords: Caliper training; technical education; vocational education; technical training; educational tool.

\section{Introduction}

Measurement is the significant stage for the all manufacturing processes. One of the most important device for the dimensional and displacement measurements is the caliper. Therefore training of measurement instruments is of the utmost importance.

The objective of this study is to develop the caliper simulators to practice by selfassessment of the caliper with vernier as computer software. Martin-Gutierrez and et al., [5] claimed that the most common method of teaching was the direct communication between teachers and students in the classroom through their attendance. This method is valid and has proven to be effective but teaching institutions are interested in introducing more productive methods to improve the learning experience and the increase in comprehension level of students, [5]. Even though the most common education is the direct education, the practical education is most important for teaching/learning technical tools or machines like flight simulator that used in pilot education.

When the scientific literature is examined, it is seen that there are many studies that have studied which is the subject of this study. Kaufmann and Meyer, [2] developed the PC gaming market to simulate physical experiments in the domain of mechanics in real time.

\footnotetext{
${ }^{a}$ Corresponding author: ggenc@marmara.edu.tr
} 
By this application students can be able to actively build own experiments and study them in a three-dimensional virtual world. Martin-Gutierrez and et al., [5] studied on Augmented Reality application to teach practice of electrical engineering. In order to improve the student's autonomy and self-ability they have developed new practical AR-manuals for being used in the Electric Machines Laboratory. Stojcic and et al., [6] presents the SustEner module power management techniques in hybrid electrical cars in their study. This project SustEner is to modernize Sustainable Electrical Energy vocational training by enhancing existing or establishing new training methods in enterprises and education Bargelis and et al., [1] developed a portal which integrated knowledge-based approach within engineering, computational sciences and management domains. They deals with a Web-based Integrated Knowledge-based Inter-discipline Study Portal (IIDSP) for teaching/learning of interdisciplinary study modules in engineering and management education. Kraiger and et al., [3] described and adapted a method known as structural assessment (SA) to be used in the evaluation of a training program for computer programming and a PC-based simulation. Lopez Soblechero, [4] studied and discussed to evaluate the distance model of official vocational education and training offered by means of a virtual learning platform. And they established both on-site classroom and online distance modes of vocational education and then training can be seen as complementary in terms of responding to the majority of modern educational needs.

The aim of vocational training is more significant to build skills for technicians. This aim is not easy and need a long time with practical applications. Practical education is the base of vocational education. For this reason, all student should have chance to practice all information that comes from theoretical education. And this is some time difficult especially for the measurement equipment.

\section{Simulation of caliper}

The caliper simulation, which will be available on website (garipgenc.com), can easily be download and setup as computer software. This application is for learning to read and use calipers not for measure something. Students or technicians can make practice according to theoretical information that given in the lessons.

The developed caliper simulation introduced by detail step by step as below;

The caliper simulation is always on the top and it runs front of all other applications on the screen as shown in Fig.1.

The caliper type can be chosen according to the vernier scales from Caliper Selector pull down menu as shown in Fig.1. There are six options according the vernier scales as 1/10, $1 / 20$ and $1 / 50$ for metric measurement system, $1 / 64,1 / 128$ and $1 / 1000$ for Whitworth measurement system.

When the caliper type is chosen, the vernier scale and line gauge scale are changed according to the caliper type.

Now, it can be moved the calipers by drag and drop from the fixed jaw or line gauge. When the mouse enters these areas, the cursor will change to show that it can be moved to four sides. When it is set the sliding jaw to measure, it must be click to clamping screw of calipers. As shown in Fig.2 a new window (zoom window) will open to show detailed vernier to see clearly which mark is aligned and able to read the measure easily.

Now it's time to check the reading value. When it is written the value of caliper to menu form and click to "Answer" button, a true sign or false sign picture will appears as shown in Fig. 3. 


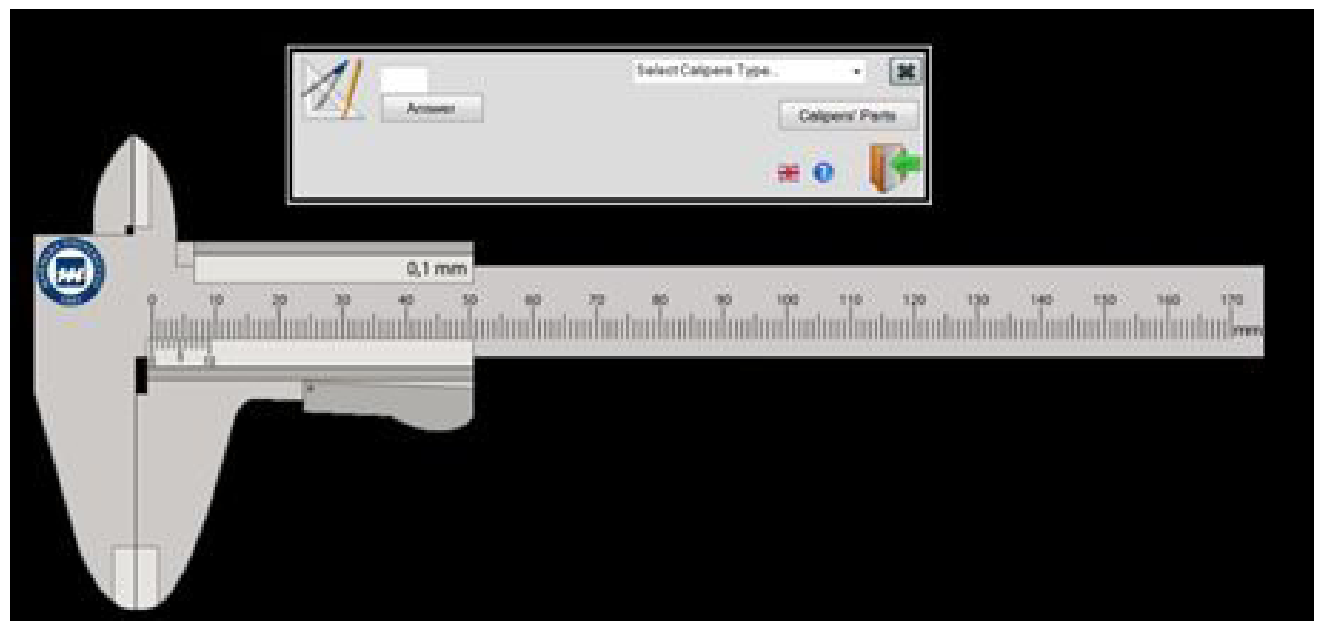

Fig.1. The main window of caliber

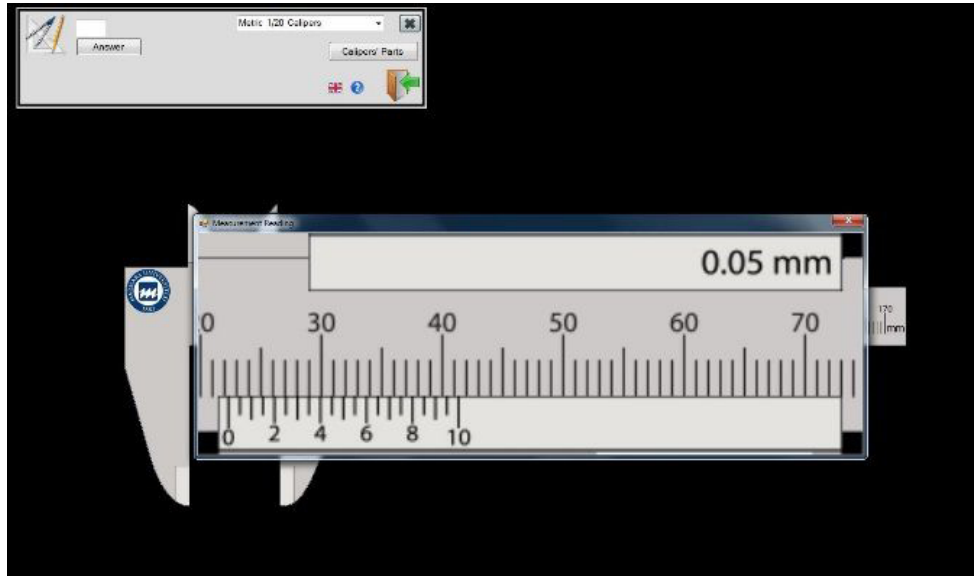

Fig. 2. The reading window of caliber
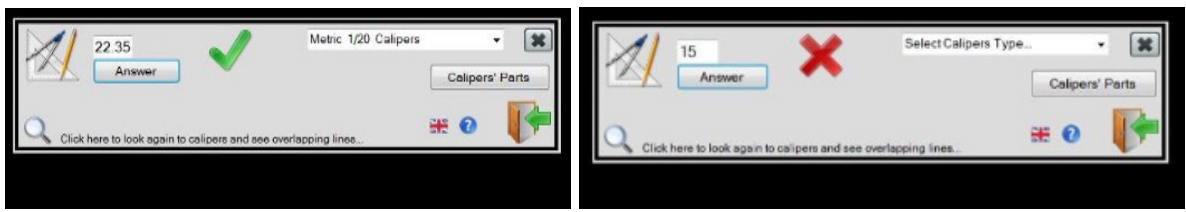

Fig. 3. The window to check the result

According the answer some explanations will be shown to take the result. If the answer is true, it will be seen "Congratulations", if not, it will be seen the true measurement as shown in Fig. 4. 


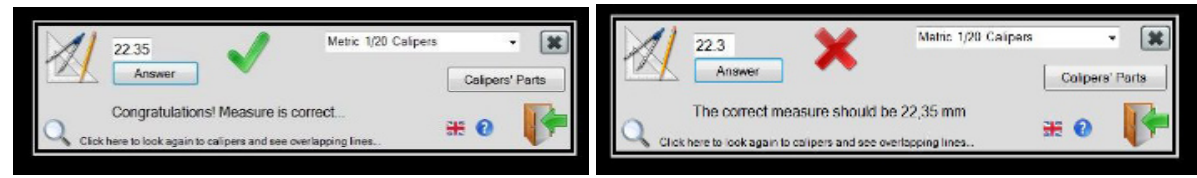

Fig. 4. The window of explanations of the result

On the left-bottom corner there is a magnifier "Search" symbol as shown in Fig.4. When clicked on this symbol detailed vernier window will appear as given in fig. 5 to show again marked aligned lines with some explanations depend on the measurement system on the window.

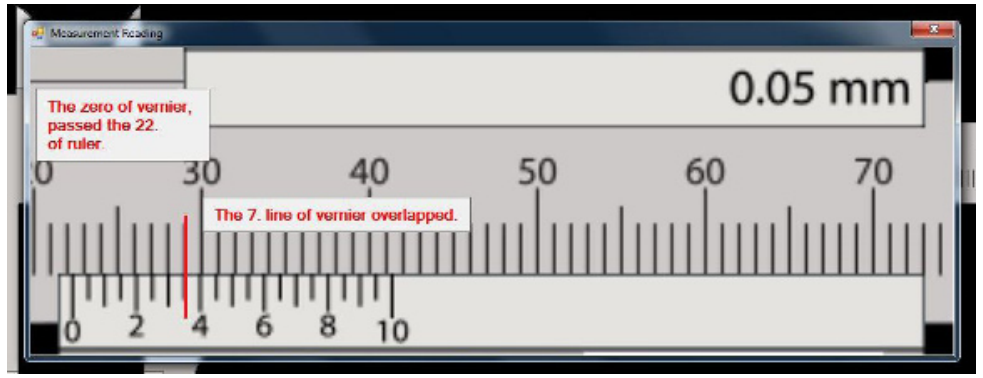

Fig. 5. Detailed vernier window

It should be noted that the magnification button (zoom window) works only after reading a measure from detailed window of calipers clamping screw. The following reasons will cancel to work this button;

1- When the simulator just is opened,

2- When the sliding jaw location is changed for any new measurement,

3- When the type of calipers is changed,

4- When the language of application is changed.

One of these reasons will realize that it must be clicked again on the clamping screw. So the magnification button will work again.

\section{Concluding remarks}

In this paper a computer application based on simulation and learning module to teach caliper as measurement tool for technical education was presented. This simulation can easily be download and setup as computer software. To the best of the authors' knowledge, this is the most important application for students to study everywhere they would like.

The simulation is based on Metric and Whitworth measurement systems.

As a conclusion, this simulation can provide benefit as a convenience for the listed below;

Learning objectives for Vocational Education and Training (VET) and Distance-based training,

Learning objectives for practical education,

Technology and technical documentation for distance practical education and measurements via the computer.

Main teaching goals were defined on that the students should improve their knowledge and practice in measurement tools. 


\section{Acknowledgement}

This research is supported by Marmara University, Scientific Research Projects Committee (BAPKO) with grant number EGT-D-130515-0231.

\section{References}

1. Bargelis, A., Mankute, R., \& Cikotiene, D., Web-based learning in engineering and management education: An IIDSP for teaching of inter-disciplinary study modules. International Journal of Engineering Education, 23(2), 378-386, (2007).

2. Kaufmann, H., \& Meyer, B., Simulating educational physical experiments in augmented reality. Paper presented at the ACM SIGGRAPH ASIA 2008 educators programme, Singapore, (2008).

3. Kraiger, K., Salas, E., \& CannonBowers, J. A., Measuring knowledge organization as a method for assessing learning during training. Human Factors, 37(4), 804-816. doi: Doi 10.1518/001872095778995535, (1995).

4. López Soblechero, M. V., A comparative study of classroom and online distance modes of official vocational education and training. Plos One, 9(5), e96052. doi: 10.1371/journal.pone.0096052, (2014).

5. Martin-Gutierrez, J., Guinters, E., \& Perez-Lopez, D. (2012). Improving strategy of self-learning in engineering: laboratories with augmented reality. World Conference on Design, Arts and Education (Dae-2012), 51, 832-839. doi: DOI 10.1016/j.sbspro.2012.08.249

6. Stojcic, G., Samonig, M. A., Hecht, S., Nussbaumer, P., \& Wolbank, T. M. (2013). Teaching power management techniques for hybrid electric cars by a interactive simulation. Paper presented at the 2013 15th European Conference on Power Electronics and Applications, EPE 2013. 